\title{
Significance of SMEs in the Czech Economy and Supporting SMEs as an Instrument of the Regional Development
}

\author{
V. Beran, J. Frková \\ SMEs (Small and Medium Enterprises) are important segments of the economic landscape of the Czech Republic, since half of economic \\ production is attributable to SMEs $(52.85 \%)$. The role of SMES in the Czech Republic is the outcome of a long history of economic \\ development and industrialization throughout the $20^{\text {th }}$ century. \\ Large enterprises prefer to locate their factories according to e range of regional opportunities. Small enterprises are more dependent on. \\ business conditions in their region. The transaction cosis are relatively high for small firms. These contraints mean that regions without an \\ attractive environment for business need to create acceptable conditions for small businesses, if they are looking for sustainable development.
}

Keywords: history of SME's, economic Power of SME's, performance indicators, comparison of industrial sectors, value added.

\section{The role of SMEs}

SMEs are an important element in the Czech economy. They have, however, had a varying role in the long history of the economic development of the country. In the first half of the $20^{\text {th }}$ century, small enterprises played a pioneering role both in Czech industry and in Central European industry generally. Hardworking craftsmen and professionals had a high reputation during the first wave of development of newly founded industrial enterprises. This situation continued before, during and after World War II. Small enterprises showed little change during this period, either in terms of structural characteristics or in terms of productivity. This period was shaped by demand conditions. In spite of the political changes, leading to nationalization in the $1950 \mathrm{~s}$, the character of the market did not change. A supplier driven market dominated, notwithstanding nationalization, the planning system, and state regulation, which provided the legal framework for economic activity. Until the 1960s, economic units consisted of small working groups. To summarize, the organization of production changed only slightly during the first economic wave of the 1955-1962 period.

The political changes in the country did, however, negatively affect economic motivation and the entrepreneurial spirit. The relative increase in economic growth during the first waves of nationalization was followed by economic distress and stagnation. Economists warned about decreasing labor productivity at that time, and this led to the initiative known as the New Economic System (NES), which was set up as a way of increasing the efficiency of the economy. The implementation of the NES, however, was far from successful in accelerating further economic progress. During this period (mainly before after 1968), industry accepted orchestrated action with enthusiasm, and started to assimilate the flood of new investments. Development took the form of massive large-scale industrialization. This second wave of industrialization was connected with the centralization of industrial capacity in large-scale organizations. The monopoly of large-scale industry was established at that time, and large industries had the main responsibility for supplying goods for the whole state. At this point in time, there existed only a few hundred state enterprises in all industrial branches. The main result of this policy was the disappearance of SMEs as an economic category in the planned economy, while the development of large-scale plants and concentration on certain economic sectors dominated the growth process. This process was partially successful, in its first phase, but the resources of qualified labor were very quickly exhausted, and industry began to suffer from lack of motivation, which later led to the ineffectiveness of industrial activities. The amount of value added per worker was not calculated in a planned economy, but it was surely very low. Innovations in industrial management decreased to a critical point and the implementation of new products became very difficult. The management of state-owned enterprises was not interested in taking new steps toward innovative action. As a result, the planned economy faced the necessity of initiating several changes and establishing a new economic milieu.

A new wave of SME development began in 1989. The economic system changed from a planned to a pluralistic market-driven economy. This change was accompanied by the reinvention of SMEs as microeconomic entities, after the dismantling of state-owned industries. The growth of SMEs seems to be still in progress. In 2000, the self-employed constituted the largest proportion of SMEs, that is $76 \%$ of the total number of small and medium-sized firms. The share of SMEs in the GDP reached $40.2 \%$ in 2000 . The highest proportion was found firstly in wholesale and retail trade $(35.9 \%$ of GDP) and secondly in services (19.26\% of GDP).

As indicated in Table 1, there are visible differences in output per employee between small (0-249 employees) and large (more than 250 employees) businesses in industry, ranging between 1552.6 thousand CZK per year in large enterprises and 1186.0 thousand CZK per year in small firms. This situation means that the larger firms are $31 \%$ more productive than the SMEs. However, the difference in labor costs per employee is not so great. The picture changes completely if we look at the need for fixed capital in order to create one job. In small enterprises, there is a need for 92.7 thousand CZK (that is about 3.1 thousand EUR) in order to generate one job, whereas large enterprises have to invest more than twice that amount ( 199.3 thousand CZK, that is 6.6 thousand EUR), which amounts to a more than $215 \%$ larger fixed capital need than in the case of smaller. 
Table 1: Structure and Economic Power of Businesses in Industry (1999)

\begin{tabular}{|l|c|c|c|}
\hline & - & $\begin{array}{c}\text { Businesses 0-249 } \\
\text { employees }\end{array}$ & $\begin{array}{c}\text { Businesses 250 + } \\
\text { employees }\end{array}$ \\
\hline Number of active businesses & 762342 & 760892 & 1450 \\
\hline Number of employees (thousand) & 3084 & 1834 & 1250 \\
\hline Output per employee per year (thousand CZK) & 1334.6 & 1186.0 & 1552.6 \\
\hline Value added per employee per year (thousand CZK) & 435.4 & 385.1 & 509.2 \\
\hline Labour costs per employee per year (thousand CZK) & 157.4 & 144.7 & 176.1 \\
\hline Investment per employee per year (thousand CZK) & 135.9 & 92.7 & 199.3 \\
\hline
\end{tabular}

Source: Czech Statistical Office 2001.

Table 2: A comparison of small and large enterprises according to performance indicators

\begin{tabular}{|l|c|c|c|}
\hline \multicolumn{1}{|c|}{ Indices } & $\begin{array}{c}\text { Value added per unit } \\
\text { of output }\end{array}$ & $\begin{array}{c}\text { Labour costs per unit } \\
\text { of output }\end{array}$ & $\begin{array}{c}\text { Investment per unit } \\
\text { of output }\end{array}$ \\
\hline Total units & 0.33 & 0.12 & 0.10 \\
\hline Businesses 0-249 employees & 0.32 & 0.12 & 0.08 \\
\hline Businesses 250+ employees & 0.33 & 0.11 & 0.13 \\
\hline
\end{tabular}

Source: Czech Statistical Office 2001.

The comparison of value added per unit of output and labor cost per unit of output, given in Table 2, shows that there are no significant differences between small and large enterprises, but there are considerable differences in the need for investment in order to create industrial output. Small businesses are less capital-intensive (0.08) than larger ones (0.13).

What do all these figures mean? Firstly, large businesses are more productive; have higher value added per employee, and also higher wage levels. The difference in productivity is higher than the difference in wages, which identifies a possible profitability gap between large and small firms. Similarly, there are massive differences in investment on equipment per employee. A large enterprise provides more than 2.1 times more investment assets than a small one. These figures indicate that the advantage of large firms, in terms of productivity, is the result of the use of more advanced equipment in the work place. Table 2 shows that the economic outputs per unit are relatively well balanced and there is no substantial difference between small and large enterprises. Nevertheless, small enterprises also have other assets and advantages, such as flexibility, the ability to adapt to volatility in the market, etc. Table 3

\begin{tabular}{|l|c|}
\hline Form of economic subjects & Number of units \\
\hline Self-employed & 1680152 \\
\hline Associations & 79112 \\
\hline $\begin{array}{l}\text { Registered companies - less } \\
\text { than 250 employees }\end{array}$ & 139879 \\
\hline Other SMEs & 228762 \\
\hline
\end{tabular}

Source: Czech Statistical Office 2002.
A category of enterprises that is very important in the Czech Republic is the self-employed. There are $16 \%$ of private entrepreneurs in business as per the trades licensing act of the Czech population.

The high number of self-employed can be explained by the possibility of working for oneself while still being employed in a company or in public service. Statistics relating to this type of work are not available, but estimations indicate that half of the self-employed are also employees. The statistics do not distinguish active entrepreneurs.

The development of SMEs still seems to be in progress. Table 3 shows the structure of registered SMEs in 2000, with the self-employed creating a broad base.

Table 4 shows the number of registered SMEs according to size.

Table 4

\begin{tabular}{|c|c|c|c|c|}
\hline \multirow{2}{*}{ Year } & \multirow{2}{*}{$\begin{array}{c}\text { Total units } \\
\text { businesses }\end{array}$} & \multicolumn{3}{|c|}{ SMEs - employees in range } \\
\cline { 3 - 5 } & & $0-9$ & $10-49$ & $50-249$ \\
\hline 2000 & 1917642 & 1862718 & 45191 & 9733 \\
\hline
\end{tabular}

Source: Czech Statistical Office 2002.

\section{Sectoral distribution of SMEs and development in the Czech Republic}

There are considerable differences between economic sectors, in terms of the share of value added in total production. Table 5 shows the differences in terms of the share of value added in the total value added generated by SMEs among the main sectors of the economy (Rathouska, 2002). The highest 
Table 5: Comparison of sectors

\begin{tabular}{|c|c|c|c|}
\hline SMEs in (year 2000) & $\begin{array}{l}\text { SMEs total production } \\
\text { (million CZK) }\end{array}$ & $\begin{array}{l}\text { SMEs total value added } \\
\text { (million } \mathrm{CZK} \text { ) }\end{array}$ & $\begin{array}{c}\text { Share of VA") to production } \\
(\%)\end{array}$ \\
\hline Industry & 739877 & 202278 & 27.3 \\
\hline $\begin{array}{l}\text { Non-financial institutions and } \\
\text { households }\end{array}$ & 2202402 & 645052 & 29.3 \\
\hline Construction & 316688 & 66479 & 21.0 \\
\hline Agriculture, forestry and fishing & 120426 & 36527 & 30.3 \\
\hline Restaurants and trade & 356839 & 179387 & 37.2 \\
\hline $\begin{array}{l}\text { Transport, storage and } \\
\text { communications }\end{array}$ & 163669 & 28109 & 17.2 \\
\hline Market services & 379216 & 132272 & 34.9 \\
\hline
\end{tabular}

Source: Czech Statistical Office 2001.

"VA.........value added

value added within production was created in the Restaurants and Trade sector, and the second highest was in Market Services. The lowest ratio is in the Construction sector.

More importantly, the shares of SMEs in different economic sectors also display considerable variation (Table 6). The largest share of SMEs in total production is in the Restaurants and Trade sector, and the lowest the Industry. Besides, the difference between the share of SMEs in total production and value added is quite considerable in different sectors. For

Table 6: The shares of SMEs in total production and value added example, in the Transport, Storage and Communications sector there is a gap between the share of production (46.2\%) and value added $(23.9 \%)$. This means that this sector is not able to create sufficient value added and is not competitive enough. According to the numbers given in Table 6, it can be seen that SMEs in construction are the most competitive.

If we compare the value added for production in particular sectors, over a six-year time period, a declining trend can be observed in all sectors (Table 7). The reason for this situa-

\begin{tabular}{|l|c|c|c|}
\hline \multicolumn{1}{|c|}{ SMEs in (year 2000) } & $\begin{array}{c}\text { Share of SMEs in terms } \\
\text { of total }{ }^{1)} \text { production }\end{array}$ & $\begin{array}{c}\text { Share of SMEs in terms of } \\
\text { total }{ }^{1)} \text { value added }\end{array}$ & Relative differences \\
\hline Industry & 34.2 & 34.7 & 0.5 \\
\hline Non-financial institutions and households & 54.2 & 53.7 & -0.5 \\
\hline Construction & 74.8 & 77.4 & 2.6 \\
\hline Agriculture, forestry and fishing & 83.4 & 81.6 & -1.8 \\
\hline Restaurants and trade & 88.3 & 85.3 & -3.0 \\
\hline Transport, storage and communications & 46.2 & 23.9 & -22.3 \\
\hline Market services & 87.8 & 82.4 & -5.4 \\
\hline
\end{tabular}

Source: Czech Statistical Office 2001.

Table 7: Value added share in terms of production (\%) - time series 1995 to 2000

\begin{tabular}{|l|l|l|l|l|l|l|}
\hline \multicolumn{1}{|c|}{ SMEs in 1995-2000 } & $\mathbf{1 9 9 5}$ & $\mathbf{1 9 9 6}$ & $\mathbf{1 9 9 7}$ & $\mathbf{1 9 9 8}$ & $\mathbf{1 9 9 9}$ & $\mathbf{2 0 0 0}$ \\
\hline Industry & 30.7 & 29.4 & 26.7 & 26.6 & 27.8 & 27.3 \\
\hline Non-financial institutions and households & 35.4 & 34.9 & $\frac{28.7}{30}$ & 30.0 & 29.4 & 29.3 \\
\hline Construction & 30.5 & 27.8 & 24.9 & 23.4 & 22.3 & 21.0 \\
\hline Agriculture, forestry and fishing & 38.5 & 35.8 & 27.2 & 30.2 & 29.8 & 30.3 \\
\hline Restaurants and trade & 43.5 & 42.8 & 35.3 & 38.5 & 37.6 & 37.2 \\
\hline Transport, storage and communications & 22.1 & 24.5 & 18.9 & 17.9 & 16.7 & 17.2 \\
\hline Market services & 40.0 & 42.2 & 31.5 & 36.2 & 34.1 & 34.9 \\
\hline
\end{tabular}

Source: Czech Statistical Office 2001. 
Table 8: Value added share in investment (\%) 1995-2000

\begin{tabular}{|l|c|c|c|c|c|c|}
\hline \multicolumn{1}{|c|}{ SMEs in 1995-2000 } & $\mathbf{1 9 9 5}$ & $\mathbf{1 9 9 6}$ & $\mathbf{1 9 9 7}$ & $\mathbf{1 9 9 8}$ & $\mathbf{1 9 9 9}$ & $\mathbf{2 0 0 0}$ \\
\hline Industry & 3.36 & 3.80 & 3.02 & 3.51 & 2.65 & 3.77 \\
\hline Non-financial institutions and households & 3.79 & 3.62 & 2.72 & 3.37 & 3.04 & 3.65 \\
\hline Construction & 7.32 & 8.50 & 6.21 & 7.43 & 7.42 & 7.64 \\
\hline Agriculture, forestry and fishing & 2.48 & 2.12 & 1.19 & 2.02 & 2.18 & 2.44 \\
\hline Restaurants and trade & 4.08 & 4.09 & 2.61 & 3.70 & 3.84 & 4.80 \\
\hline Transport, storage and communications & 2.98 & 3.10 & 2.13 & 2.92 & 2.31 & 2.17 \\
\hline Market services & 3.77 & 2.80 & 2.22 & 2.69 & 2.55 & 2.69 \\
\hline
\end{tabular}

Source: Czech Statistical Office 2001

tion is that the value added growth index for the 1995/2000 period was 1.38 , while the intermediate consumption growth index reached 1.72 in the same period.

Further information is given in Table 8. It is necessary to pay more attention to the indicator "Share of value added in investment", since investment has a multiplier effect on production. One unit of investment creates more than seven units of value added in the construction sector. The main reason is that Construction has a high share of value added in production and at the same time it has the highest increase in the price index for the 1995-2000 period (about 10\%). Other sectors have lower price index growth and need higher investment input. The general trend in the Czech Republic's economic development explains the changes in the share of value added in investment during the 1995-2000 period, which are given in Table 8. Fig. 1 presents the index of GDP per capita during the 1995-2001 period and predictions for the 2002-2004 period. This figure shows the recession that occurred between 1996-1998, which was due to the fast growth of domestic consumption, a high import deficit, and relatively low productivity growth in the industry and services sectors. This pattern of growth in GDP is reflected in the growth of the sectors described in Table 7 and Table 8 .

\section{Measures to support SMEs for regional development}

Although SMEs are flexible in their production organization, they are confined to certain localities, due to the immobility of their main resources. Individuals linked to SMEs are connected to their place of residence, housing, etc. Large enterprises prefer to locate their factories according to a range of regional opportunities. Small enterprises are more dependent on business conditions in their region. The transaction costs are relatively high for small firms. These constraints mean that regions without an attractive environment for business need to create acceptable conditions for small businesses, if they are looking for sustainable development.

In the near future, due to their proximity to the developed countries of the European Union, the Czech regions are expected to get an influx of capital and know-how, which will aim to utilize the available qualified labor force. Also, after accession to the European Union, new opportunities in the unified market may have a positive impact on several regions, and the financial support provided by European

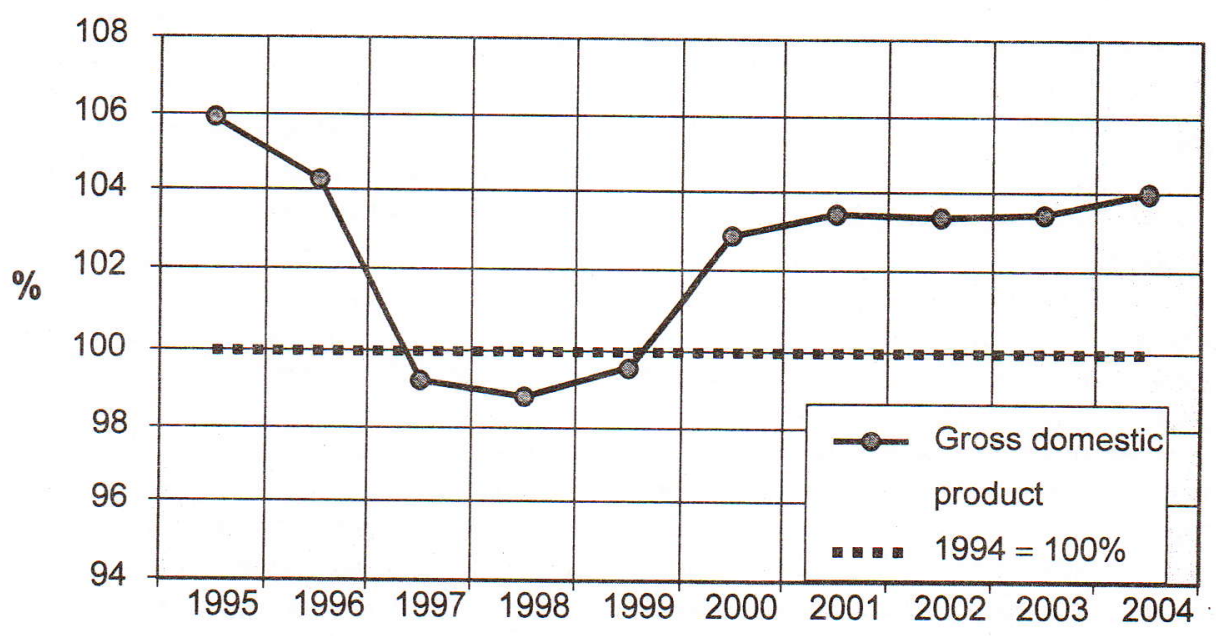

Fig. 1: Real growth of GDP in the transition period of CR 
Union programmes may accelerate the restructuring process in industry and agriculture. A prerequisite for these growth scenarios is the incorporation of SMEs into the restructuring process, as one of the major sources of innovation, although many of the changes so far have been focused on large-scale industry. There are several points that the new policies need to take into account. Firstly, industrial centers, functioning as development poles, are important in the creation of seedbeds for SMEs. Secondly, trans-border cooperation of local manufacturing industry, agriculture and tourism in border regions is vital in acquiring structural funds from the European Union. Thirdly, the existing government policies intended to support SMEs in the Czech Republic should be used more effectively. The Ministry of Industry and Trade sets up special programmes every year in support of SMEs. If they are to make use of the existing incentives, SMEs have to fulfill certain conditions, such as that they must employ less than 250 employees, annual sales must not exceed 250 million CZK ( 7 million EUR), and they must be independent units (no more than $25 \%$ of the capital may owned by a company which is not an SME). There are also programmes financed by the state budget; and assistance is provided in certain fields, such as facilitating access to funding (programmes: Guarantee, Credit, Market, etc.), employment support (Special programme), reinforcing their position in the market and their improving competitive advantage (programmes: Cooperation, Design, Consultancy, etc.), regional programmes (Region, Regeneration, Village, Mobile Salesroom, etc.), and so on. There are also banking and financial schemes in support of SMEs. The Small Loan Programme provides subsidies for financing development projects. The range of this loan is from $0.3-1$ million CZK, for a period of 4 years, and the interest rate is the prime rate plus $1 \%$. The industry programme that has been announced by the Ministry of Industry supports subprogrammes called Transfer and Quality. The aim of this programme is to introduce new technologies and products, which will initiate $\mathrm{R} \& \mathrm{D}$ activities, in collaboration with domestic universities, or using external suppliers. The Transfer programme covers up to $50 \%$ of the cost of the accepted proposals to a maximum of 3.5 million CZK on projects (about 100000 EUR). The aim of Quality is to support projects specializing in information technology (IT) development and information control systems, test systems, methodology and diagnostics. Quality pays up to $50 \%$ of the cost of approved proposals to a maximum of $200000 \mathrm{CZK}$ on projects (7 $000 \mathrm{EUR}$ ).

There are 29 Regional Advisory and Information Centres (RPICs) and 5 Business Innovation Centres (BICs) in the Czech Republic, aimed at supporting the innovative capacities of firms. RPICs mostly provide advisory services for entrepreneurs, such as help in establishing new companies, assistance in making business plans, mediating bank credits, creating new jobs, providing information about support programmes available in their region, organizing educational seminars for entrepreneurs, etc. Business Innovation Centers (BICs) focus on supporting innovative businesses, transfer of technologies from abroad, the implementation of $R \& D$ outcomes, and making use of the opportunities provided by the European network of business and innovation centers, in addition to basic advisory services. Their special task is to provide support for companies located in so-called business incubators. The standard services provided by RPICs and BICs are intro- ductory consultation, business advisory services, subsidies for innovative firms in incubalor centres, as well as the training of entrepreneurs. The amount allocated from the state budget to support SMEs is quite low; approximately 1 million EUR, and obviously such a low level of financial help cannot do much to promote SMEs. At the regional level, municipal authorities are not able to devote any resources to promote SMEs in their region.

The support system designed for SMEs in the Czech Republic seems well defined, well advised and well coordinated. Low financial resources, however, are the main obstacles to the realization of its intended purpose. Obviously, regional development has to be seen as a result of increasing market relations and not necessarily as a result of state economic policy. In regional development, SMEs play an important role in balancing the market consisting of large enterprises, especially in the service sectors and in innovative production activities. Nevertheless, SMEs have to act very carefully. One large mistake or wrong decision can be a serious threat to their existence. Therefore, the management of small enterprises has to behave more carefully than that of large enterprises.

Therefore it is necessary to develop more effective methods of helping small businesses. A small enterprise is influenced not only by the local economic conditions, but also by external forces. The impact of national macro-economic conditions is usually unavoidable.

\section{Obstacles to further development of SMEs in the Czech Republic}

An improving, but still imperfect, legal framework, continuing privatization, and insufficient adaptability to world market conditions characterize the economic environment in the Czech Republic. In recent years, the national economy has suffered from lack of domestic capital, low levels of investment in industry and a general decrease in the fixed capital investment rate. In general, the economic potential is relatively limited. The low level of competitiveness is the result of outdated technology and a low level of innovation. A substantial number of industrial and agricultural enterprises (mainly SMEs) are in a difficult economic situation, due to under-capitalization, latent or real insolvency and increasing debts. They suffer from unfavorable technical conditions and a decrease in the number of qualified workers. In-firm research activities are limited. Similar conditions exist in agriculture, as is apparent from the low levels of agricultural production, low levels of competitiveness in the rural economy and the insufficient facilities of smaller municipalities.

The proportion of GDP devoted to education is below the EU average. The consequence of this situation is a low percentage of university-educated people, permanent under-education, poorly equipped schools and a decrease in the number of qualified teachers. The education system is not sufficiently connected to the labour markets. The same kind of disadvantages appear in utility services. Road networks are insufficiently connected to the greater European network, the highway networks are unevenly distributed, and highway connections in some regions (southern Bohemia, northern Moravia) are lacking. Peripheral regions face increasing deficiencies in their transportation infrastructure. 
Energy supply and distribution are still monopolistic. The pricing model used in energy distribution and water supply is distorted, which leads to high water losses and high failure rates in obsolete networks. The natural environment in the Czech Republic also reveals many problems. These problems include high levels industrial air pollution in North-western Bohemia, the Ostrava region and Prague, and increasing concentrations of transport emissions in most of the big towns. Emissions, raw material exploitation and unsuitable forms of tourism are doing damage to several environmentally sensitive locations. Waste disposal is not controlled, wastes are not re-used or prevented at source. Excessive utilization of non-renewable sources is still continuing, and there is a preference for "pipe-end" technologies, etc., as a consequence of a lack of, or low efficiency of, suitable economic and normative tools.

In summary, the free market economy has been running for only 12 years in the Czech Republic, and the new legal system has not been able to remove the habits of the past. Some entrepreneurs do not respect business standards. The enforcement of laws is poor and this situation facilitates dishonest practices. SMEs, which are especially vulnerable to these conditions, have only a limited ability to sustain their own viability. Beside, loss of continuity and lack of experiences play its important role.

\section{Conclusions}

The role of SMEs in the Czech Republic is the outcome of a long history of economic development and industrialization throughout the $20^{\text {th }}$ century. The industrial basis has passed through several stages. The change from disaggregated small-scale manufacturing to relatively concentrated industry, on a private basis, which was the experience of the first half of the $20^{\text {th }}$ century, was followed by the concentration of state-owned enterprises in the planned economy. The deregulation and privatization of the last decade led to the revitalization of entrepreneurship and the creation of many small or middle-sized enterprises. The market driven economy promptly highlighted the weak and strong points of enterprises, and the regional context of entrepreneurship became an important factor in economic performance.

SMEs are important segments of the economic landscape of the Czech Republic, since half of economic production is attributable to SMEs ( $52.85 \%)$. The main concentration areas of SMEs are Agriculture, Forestry and Fishing, Restaurants and Trade, Market Services, and Construction, in which sectors the share of small and medium-sized firms in total production is higher than $80 \%$. On the other hand, the share of SMEs in total manufacturing production is only $35.25 \%$, according to 2000 figures. This outcome, and several of the problems in manufacturing, is the result of the policies followed in the planned economy. The main problems are low economic efficiency, suppression of interest in innovation and technical progress, low productivity, high percentage of labor costs in the production, value, etc.

Currently, the incentives to growth are oriented not only to large-scale industry, services and other segments of the economy, but also to small and medium-sized enterprises. The support provided for the factors promoting development has led to the rediscovery of SMEs as an impor- tant instrument of economic progress. The ability of SMEs to operate within the new global economy is more limited since globally operating enterprises have a greater ability to succeed in the global market and to deal with economic problems. However, there is a need to balance business opportunities between large and small or medium-sized enterprises, in order to initiate and sustain regional development. It should not be forgotten that SMEs are important not only for their role in economic growth, but also for their contribution to the strengthening of social cohesion.

In spite of the lower value added per worker created by SMEs, the welfare attributes of small entrepreneurship make SMEs important for local and regional development. From the economic point of view, large public enterprises may have an advantage compared with small enterprises, since they can support the unemployed and the socially handicapped, but SMEs are able to substitute for several public social services in the regions. SME support schemes are cheaper than direct payments of social services and unemployment benefits by governments. SMEs are crucial in the development of the regions. The investment requirements of SMEs are only half as demanding as the investment requirements of large-scale enterprises. In addition to this aspect of SMEs, they are more flexible and have the ability to create changes and innovations. That is why SMEs are the subject of attention, not only in the Czech Republic, but also in the European Union.

\section{References}

[1] Behrens, A.: Regional Gross Domestic Product in Candidate Countries 1999,

www.europa.eu.int/comm/eurostat/, 2002.

[2] Beran, V.: Development Strategies II: Regions and Municipalities, CTU in Prague, 2000.

[3] Beran, V.: Management of Sustainable Life Cycle Development of Regions and their Building Structures. CTU in Prague, 2001

[4] Czech Statistical Office: Small and Medium Sized Enterprises in Industry. Prague: Czech Statistical Office, 2001.

[5] Frkova, J.: The Individual Enterprise. CTU in Prague, 1999.

[6] Rathouska, B.: Selected Economic Results of Small and Medium-sized Enterprises in the CR in 1995-2000. Czech Statistical Office, 2002.

Doc. Ing. Václav Beran, DrSc.

phone: +420224354526

e-mail: beran@fsv.cvut.cz

Ing. Jana Frková

phone: +420224354532

Department of Economics and Management in Civil Engineering

Czech Technical University in Prague

Faculty of Civil Engineering

Thákurova 7

16629 Prague 6, Czech Republic 